\title{
Dissolution mechanism of fly ash to quantify the reactive aluminosilicates in geopolymerisation
}

\author{
Kuenzel, Carsten; Ranjbar, Navid
}

Published in:

Resources, Conservation and Recycling

Link to article, DOI:

10.1016/j.resconrec.2019.104421

Publication date:

2019

Document Version

Peer reviewed version

Link back to DTU Orbit

Citation (APA):

Kuenzel, C., \& Ranjbar, N. (2019). Dissolution mechanism of fly ash to quantify the reactive aluminosilicates in geopolymerisation. Resources, Conservation and Recycling, 150, [104421].

https://doi.org/10.1016/j.resconrec.2019.104421

\section{General rights}

Copyright and moral rights for the publications made accessible in the public portal are retained by the authors and/or other copyright owners and it is a condition of accessing publications that users recognise and abide by the legal requirements associated with these rights.

- Users may download and print one copy of any publication from the public portal for the purpose of private study or research.

- You may not further distribute the material or use it for any profit-making activity or commercial gain

- You may freely distribute the URL identifying the publication in the public portal

If you believe that this document breaches copyright please contact us providing details, and we will remove access to the work immediately and investigate your claim 


\title{
Dissolution mechanism of fly ash to quantify the reactive aluminosilicates in
}

\section{geopolymerisation}

\author{
Carsten Kuenzel ${ }^{1}$, Navid Ranjbar ${ }^{2,3,4 *}$ \\ ${ }^{1}$ Department of Civil and Environmental Engineering, Imperial College London, UK \\ ${ }^{2}$ Department of Mechanical Engineering, Technical University of Denmark, $2800 \mathrm{Kgs}$ Lyngby, \\ Denmark \\ ${ }^{3}$ Department of Health Technology, Technical University of Denmark, $2800 \mathrm{Kgs.}$. Lyngby, \\ Denmark ${ }^{4}$ Department of Civil, Environmental and Geomatic Engineering, University College \\ London, London WC1E 6BT, UK
}

List of keywords: fly ash; reactivity; geopolymers; aluminosilicates; characterization;

\begin{abstract}
Predicting of fly ash (FA) performance in alkali environment is difficult due to its heterogeneous nature. This paper investigates the dissolution process of FA in $\mathrm{NaOH}$-activated geopolymers toward quantification of its reactivity. Dissolution rates were influenced much more by temperature $\left(25-145^{\circ} \mathrm{C}\right)$ and time $(2-24 \mathrm{~h})$ than by $\mathrm{NaOH}$ molarity $(8-16 \mathrm{M})$. Higher temperatures increased the kinetic energy of the system, thus increasing the effectiveness of solute molecular bond breakage by solvent molecules and intermolecular attraction. Analysis by FTIR, ICP, XRD and SEM-EDS implies that FA consists of reactive materials, partially reactive materials, and inert materials. The reactive materials dissolve rapidly during geopolymerisation. The partially reactive materials are cenospheres, whose outer vitreous $\mathrm{Si}$ shell dissolves gradually, while the inert materials remain un-reacted. To avoid overestimating or underestimating the reactive material content in FA, it is proposed to modify the dissolution method to match the intended curing temperature and to set the dissolution test duration fitting with the initial setting time of the geopolymer paste at the curing temperature of interest. It is not only the quantity of reactive material that is important but also the $\mathrm{Si} / \mathrm{Al}$ ratio of the reactive material. Consequently, it is recommended that quantification of reactive material be analysed by ICP dissolution rather than EDS analyses of the undissolved material.
\end{abstract}

${ }^{*}$ Corresponding author's e.mail address naran@mek.dtu.dk (N.Ranjbar). 


\section{Introduction}

Geopolymers are an inorganic polymer and currently being considered as an alternative to conventional cement due to their technical performance and low carbon footprint (Provis and Van Deventer, 2009). These inorganic polymers can be produced from a wide range of different natural and waste materials which are rich in aluminosilicates. Several materials have already been proposed, such as coal fly ash (FA) (Fernández-Jiménez and Palomo, 2005; Ranjbar and Kuenzel, 2017b), metakoalin (MK) (Kuenzel et al., 2013; Kuenzel et al., 2012), volcanic ash (VA) (Djobo et al., 2016; Ranjbar et al., 2018), granite waste (GW) (Tchadjié et al., 2016), ground granulated blast furnace slag (GGBFS) (Cheng and Chiu, 2003; Fang et al., 2018), and palm oil fuel ash (POFA) (Ranjbar et al., 2014a). Due to cost and a history of previous usage in the construction industry, most research has focused on waste materials like FA instead of metakaolin (Komnitsas and Zaharaki, 2007).

In order to synthesise geopolymers, these precursors are dissolved in alkali hydroxide and/or alkali silicate solutions. After dissolution, a gel is formed which solidifies and results in a material with properties similar to cement. This geopolymerisation sequence can be broadly split into two periods: (i) dissolution-hydrolysis and (ii) hydrolysis-polycondensation, which occur simultaneously once the aluminosilicate materials are mixed with the activator solution (Ranjbar et al., 2014b; Wang et al., 2005; Zuhua et al., 2009).

During the dissolution-hydrolysis step the dissolution of solid precursors and the release of aluminate and silicate monomers occurs. This dissolution is followed by a hydrolysis between the monomers. This continuous process results in the formation of dissolved aluminosilicates which react further to oligomers (Fernández-Jiménez et al., 2005). By considering only mass and charge 
balances dissolution and hydrolysis of raw aluminosilicate minerals under alkaline condition, the dissolution and hydrolysis reactions can be written as (Weng and Sagoe-Crentsil, 2007):

$$
\begin{aligned}
& \mathrm{Al}_{2} \mathrm{O}_{3}+3 \mathrm{H}_{2} \mathrm{O}+2 \mathrm{OH}^{-} \rightarrow 2 \mathrm{Al}(\mathrm{OH})_{4}^{-} \\
& \mathrm{SiO}_{2}+\mathrm{H}_{2} \mathrm{O}+\mathrm{OH}^{-} \rightarrow\left[\mathrm{SiO}(\mathrm{OH})_{3}\right]^{-} \\
& \mathrm{SiO}_{2}+2 \mathrm{OH}^{-} \rightarrow\left[\mathrm{SiO}_{2}(\mathrm{OH})_{2}\right]^{2-}
\end{aligned}
$$

Furthermore, these reactions are depending on $\mathrm{pH}$, temperature during dissolution as well as the chemical reactivity of feedstock (Weng and Sagoe-Crentsil, 2007).

During the second stage, the oligomers undergo a polycondensation reaction which results in the setting and hardening of the gel and the formation of a new three dimensional aluminosilicate network, containing Si-O-Si and Si-O-Al bonds in a highly cross-linked amorphous network (Hajimohammadi, 2010; Provis, J. and Van Deventer, J., 2007; Provis, J.L. and van Deventer, J.S., 2007). This formed network has a direct influence on the final mechanical properties of geopolymers (Davidovits, 2008).

It must be noted that depending on the precursor, particles can remain unreacted or partially reacted in the hardened gel network (Aughenbaugh et al., 2013; Chen-Tan et al., 2009; Ranjbar et al., 2017). This has not been observed for metakaolin but for waste materials such as FA (Aughenbaugh et al., 2013; Chen-Tan et al., 2009; Kuenzel et al., 2013; Ranjbar et al., 2017). Various publications focusing on FA based geopolymers showed reacted materials next to apparently unreacted spherical particles. It has been assumed that these spherical particles are inert FA but they have never been investigated (Ranjbar et al., 2017). This fact is quite surprising because the dissolution kinetics of waste materials is crucial for the final mechanical properties for geopolymers. To further design and optimise geopolymer formulations, it is important to understand the dissolution process of waste materials. Hence, the dissolution process of FA has 
been investigated by altering the alkali environment and quantification of the reactive amount of material.

\section{Materials and methods}

\subsection{Material characterization}

In this study a low calcium FA, class F, supplied by Lafarge Malayan Cement Bhd (Malaysia), was used. The chemical composition of FA is shown in Table 1. The FA was rich in $\mathrm{SiO}_{2}$, had a relatively low $\mathrm{Al}_{2} \mathrm{O}_{3}$ concentration and contained some impurities, mainly $\mathrm{Fe}_{2} \mathrm{O}_{3}$. The LOI of the samples as obtained by thermogravimetric analysis was about $6 \%$. The particle size distribution was measured using Mastersizers Malvern Instruments. Following results have been measured: $\mathrm{d}_{10}=0.4 \mu \mathrm{m}, \mathrm{d}_{50}=12.2 \mu \mathrm{m}$, and $\mathrm{d}_{90}=70 \mu \mathrm{m}$.

To dissolve FA, sodium hydroxide $(\mathrm{NaOH})$ pellets with a purity of $99 \%$ from Merck (Germany) were used. The $\mathrm{NaOH}$ solution had been prepared at least $24 \mathrm{~h}$ before use to ensure that the solution had reached an equilibrium with the ambient temperature.

Table 1: XRF analysis of FA.

\begin{tabular}{cccccccccccc}
\hline $\begin{array}{c}\text { Aluminosilicate } \\
\text { sources }\end{array}$ & $\mathrm{SiO}_{2}$ & $\mathrm{Al}_{2} \mathrm{O}_{3}$ & $\mathrm{CaO}$ & $\mathrm{Fe}_{2} \mathrm{O}_{3}$ & $\mathrm{TiO}_{2}$ & $\mathrm{P}_{2} \mathrm{O}_{5}$ & $\mathrm{MgO}$ & $\mathrm{SO}_{3}$ & $\mathrm{~K}_{2} \mathrm{O}$ & $\mathrm{Na}_{2} \mathrm{O}$ & $\mathrm{MnO}$ \\
\hline $\mathrm{FA}$ & 75.76 & 15.86 & 0.95 & 3.90 & 0.97 & 0.21 & 0.26 & 0.35 & 1.14 & 0.16 & 0.06 \\
\hline
\end{tabular}

\subsection{Background information: comparison of dissolution mediums}

In this work $\mathrm{NaOH}$ has been used to dissolve the FA precursors although in recent works several other solvents have been used such as: picric acid (Li et al., 1985; Ohsawa et al., 1985); salicylic acid (Gutteridge, 1979; Ogawa et al., 1980); hydrogen fluoride solutions; combination of ethylene diamine tetra acetic acid with triethanolamine, hydrofluoric acid (Aughenbaugh, 2013; Ohsawa et al., 1985) and $\mathrm{NaOH}$ or $\mathrm{KOH}$ solutions (Brouwers and Van Eijk, 2002; Pietersen et al., 1989; 
Ranjbar and Kuenzel, 2017b). Depending on the type, $\mathrm{pH}$ and temperature of the solution each of these have some limitations and hence are only suggested for particular applications (Aughenbaugh, 2013; Fraay et al., 1989; Kuenzel et al., 2013; Ruiz-Santaquiteria C, 2011). For example, it was found that acidic solutions do not only dissolve reactive $\mathrm{Al}$ and $\mathrm{Si}$ but also "unreactive" quartz (Aughenbaugh, 2013; Ohsawa et al., 1985). Some reactive silica has been shown to precipitate in acidic environments, resulting in an overestimation of the unreactive fraction (Luke and Glasser, 1987). Such precipitation has not been observed in $\mathrm{NaOH}$ and $\mathrm{KOH}$ solutions. Pietersen et al. investigated the reactivity of FA based on the dissolved amorphous content at very low solid to liquid ratio (1:1000 by weight) in a high $\mathrm{NaOH}$ solution. They concluded that glass chemistry has a little influence on the reactivity and dissolution rate of $\mathrm{Al}, \mathrm{Si}$ and $\mathrm{K}$ (Brouwers and Van Eijk, 2002; Pietersen et al., 1989). Moreover, depending on the solid to liquid ratio, Brouwers and van Eijk (Brouwers and Van Eijk, 2002) showed that, in low solid to liquid ratio $(1: 1000)$ systems, the outer layer of the FA spherical particles could be less reactive in comparison to the inner particles that trapped inside larger particles. Conversely, Chen Tan et al reported that for higher solid to liquid ratio (1:50) the reactivity of the outer and inner particles are similar (Chen-Tan et al., 2009). Apart from the concentration of alkali materials, the type is another significant factor. $\mathrm{NaOH}$ is often preferred to $\mathrm{KOH}$ as it is the most used hydroxide activator in geopolymer synthesis. This is due to the low cost, wide availability and low viscosity (Provis and Van Deventer, 2009). Therefore, $\mathrm{NaOH}$ solutions are the first choice when a dissolution method is used. 


\subsection{Testing methods}

To determine the degree of precursor reactivity, FA was dried at $250^{\circ} \mathrm{C}$ for an hour to evaporate remaining moisture. This drying temperature was chosen because according to TGA data, all pore water is removed (Ranjbar and Kuenzel, 2017b). Then, 1g of dried ash was stirred in 100ml of $\mathrm{NaOH}$ solution at various temperatures $\left(25-145^{\circ} \mathrm{C}\right)$, for various times $(2-24 \mathrm{~h})$ and with $\mathrm{NaOH}$ of different molarity (8-16M). Dissolution tests and the variable combinations are summarised in Table 2. For dissolution experiments with temperatures above $100^{\circ} \mathrm{C}$, it was necessary to use a stopper on flasks to avoid excessive evaporation. Furthermore, the stopper caused a slight increase of pressure in the vessel and the boiling temperature was shifted to higher temperatures. The time variable and molarity variable experiments were conducted at a constant temperature of $65^{\circ} \mathrm{C}$. This temperature had been chosen because this is generally considered as the preferred curing temperature for FA based geopolymers (Hardjito et al., 2004; Ranjbar and Kuenzel, 2017b; Swanepoel and Strydom, 2002). Except for the time variable experiments, the duration of all dissolution tests was $2 \mathrm{~h}$. This time was chosen because at $65^{\circ} \mathrm{C}$, initial hardening begins after $2 \mathrm{~h}$.

To separate the residue from the liquid after stirring, the suspension was centrifuged at 6000rpm for 3 minutes using a Hettich EBA 12 centrifuge (Andreas Hettich GmbH and Co., Tuttlingen, Germany).

The liquid phase was collected from the supernatant, filtered using $0.45 \mu \mathrm{m}$ thickness Whatman cellulose nitrate membrane filters (Germany), mixed with $60 \% \mathrm{HNO}_{3}$ to a concentration of $0.4 \mathrm{M}$ $\mathrm{HNO}_{3}$ and analysed using inductively coupled plasma optical emission spectroscopy (ICP-OES, Perkin Elmer model 8300).

The solid residue from the centrifuge was washed with distilled water until the $\mathrm{pH}$ was neutral, dried for $1 \mathrm{~h}$ at $250^{\circ} \mathrm{C}$ and the mass recorded (Ranjbar and Kuenzel, 2017b). Noteworthy, the drying 
procedure was kept the same as pre-drying of FA to keep the status of the pore and structural waters similar. The authors were aware that a temperature of $1000^{\circ} \mathrm{C}$ is normally used to determine the un-dissolved amount because during the dissolution of FA hydroxide groups are formed on the surface. Only when the washed FA is heated to $1000^{\circ} \mathrm{C}$, it can be ensured that these hydroxide groups have been changed into oxides. However, at these temperatures sintering of the residue occurs during which the particles change their shape. Furthermore, the determination of the exact quantity of remaining material was only of secondary importance to this study, whose main focus was on the microstructure of undissolved materials. When sintering occurs, the microstructure changes and a misinterpretation of the SEM images was possible.

Table 2: Test parameters used in this study to assess FA dissolution in $\mathrm{NaOH}$.

\begin{tabular}{|c|c|c|c|}
\hline Experiment & $\begin{array}{l}\mathrm{NaOH} \text { molarity } \\
\text { (M) }\end{array}$ & $\begin{array}{l}\text { Time } \\
\text { (h) }\end{array}$ & Temperature $\left({ }^{\circ} \mathrm{C}\right)$ \\
\hline \multirow{6}{*}{1} & 8 & 1 & $65^{*}$ \\
\hline & 8 & 2 & 65 \\
\hline & 8 & 4 & 65 \\
\hline & 8 & 6 & 65 \\
\hline & 8 & 12 & 65 \\
\hline & 8 & 24 & 65 \\
\hline \multirow{7}{*}{2} & 8 & 2 & 25 \\
\hline & 8 & 2 & 45 \\
\hline & 8 & 2 & 65 \\
\hline & 8 & 2 & 85 \\
\hline & 8 & 2 & 105 \\
\hline & 8 & 2 & 125 \\
\hline & 8 & 2 & 145 \\
\hline \multirow{5}{*}{3} & 8 & 2 & 65 \\
\hline & 10 & 2 & 65 \\
\hline & 12 & 2 & 65 \\
\hline & 14 & 2 & 65 \\
\hline & 16 & 2 & 65 \\
\hline
\end{tabular}

Setting time was evaluated in accordance with ASTM-C191-13, using a manual Vicat needle test machine at $65^{\circ} \mathrm{C}$. However, the hot curing resulted in a fast evaporation of surface water at the top layer of geopolymer, and therefore, a pseudo fast setting occurred. To reduce this effect, the surface of the samples has been covered with a thin oil layer (Ranjbar and Kuenzel, 2017b; Ranjbar et al., 2016). 
Fourier transform infrared spectroscopy (FTIR) analysis was carried out using a Perkin Elmer System series 2000 spectrophotometer in a frequency range of $4000-400 \mathrm{~cm}^{-1}$ to identify the functional group of the composites using the pure powder without the aid of $\mathrm{KBr}$.

X-ray diffraction (XRD) patterns were measured on an Empyrean PANALYTICAL diffractometer with monochromated $\mathrm{Cu} \mathrm{K} \alpha$ radiation $(\lambda=1.54056 \AA)$, operated at $45 \mathrm{kV}$ and $40 \mathrm{~mA}$ with a step size of $0.026^{\circ}$ and a scanning rate of $0.1 \mathrm{deg} \mathrm{s}^{-1}$ in the $2 \theta$ range of 20 to $70^{\circ}$.

Field emission scanning electron microscopy (FESEM-AURIGA 60 and Quanta FEG 450) was used to observe the microstructures of aluminosilicate particles before and after exposure to $\mathrm{NaOH}$ solution. Elemental analysis of scanning electron microscopy (SEM) images has been carried out using an energy dispersive spectrometer at $15 \mathrm{kV}$ (EDS) fully embedded into a Phenom ProX system. To evaluate the major elemental concentration that exists in the residues, EDS was performed for at least 10 points $(\sim 160 \times 160 \mu \mathrm{m})$ for each specimen and the average value taken. The elemental mapping function of EDS was also used for visual demonstration of the available elements in the materials. The SEM and EDS samples were not coated.

\section{Results and discussion}

\subsection{Setting time of FA based geopolymers}

Setting time was measured using Vicat needle at $65^{\circ} \mathrm{C}$. This temperature was chosen because this temperature is the most common reaction temperature for FA to obtain the optimum mechanical properties (Ranjbar and Kuenzel, 2017b). It can be seen that hardening starts after around 60 minutes and final setting is reached after 120 minutes. This is in agreement with previous studies (Ranjbar et al., 2016). 


\subsection{Dissolution of FA precursors}

Figure 1 shows the dissolution of FA as a function of time, temperature and $\mathrm{NaOH}$ molarity measured by mass change. In Figure 1a, it can be seen that the degree of reaction is continuously increasing over time, however an equilibrium is reached by $12 \mathrm{~h}$, after which only minor amounts dissolve further. This indicates that during the curing and initial hardening of geopolymers most of the reactive material is available for the reaction. Figure $1 \mathrm{~b}$ shows the dissolution of waste materials over various temperatures within $2 \mathrm{~h}$. It can be seen that elevated temperatures are important to accelerate dissolution of a sufficient amount of precursor for the geopolymerisation reaction. This data is in agreement with previous work and shows why at least a temperature of about $65^{\circ} \mathrm{C}$ is required to accelerate the reaction (Aredes et al., 2015; Chindaprasirt et al., 2007; Hardjito et al., 2004; Mo et al., 2014). Figure 1c shows the influence of $\mathrm{NaOH}$ molarity on the dissolution at a constant temperature of $65^{\circ} \mathrm{C}$. It can be seen that the molarity of $\mathrm{NaOH}$ solution in this concentration range does not significantly influence the dissolution rate. This result was expected due to the high liquid/solid ratio. $\mathrm{NaOH}$ is only required to ensure an alkali environment and does not influence the precursor dissolution. These results show that $\sim 25 \mathrm{wt} . \%$ of the FA is unreactive and remain in the matrix as filler. Furthermore, the dissolution of FA is temperature controlled and almost all the materials dissolved at $65^{\circ} \mathrm{C}$ after $24 \mathrm{~h}$ are dissolved in $2 \mathrm{~h}$ at $145^{\circ} \mathrm{C}$. 

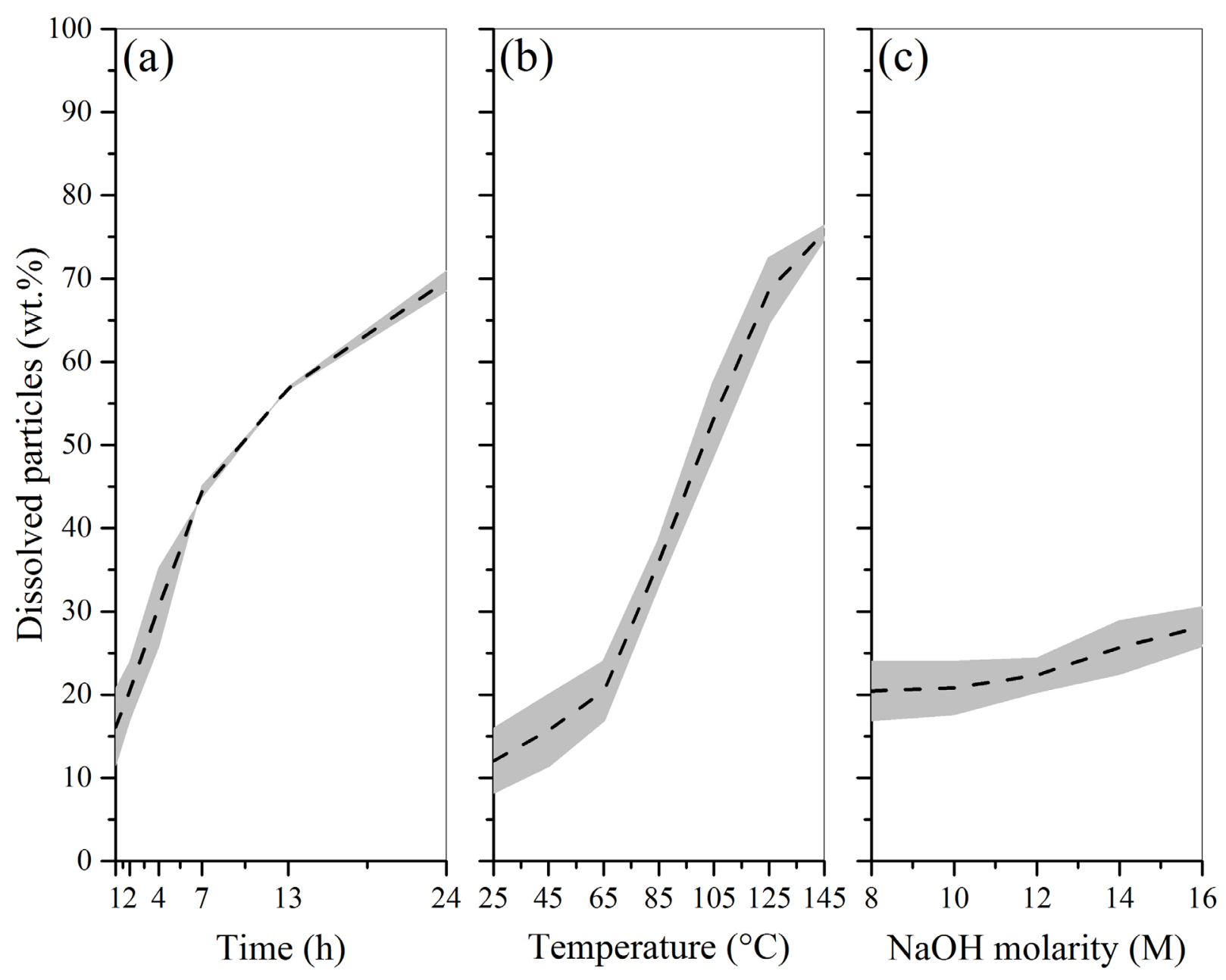

Figure 1: Dissolved mass percentages of aluminosilicate sources in $\mathrm{NaOH}$ as a function of a) time; b) temperature and c) $\mathrm{NaOH}$ molarity. Unless specifically varied, the temperatures were $65^{\circ} \mathrm{C}$, dissolution duration $2 \mathrm{~h}$ and $\mathrm{NaOH}$ molarity $8 \mathrm{M}$. The grey area marks the error of this method.

\subsection{Dissolved FA precursors - Inductively coupled plasma optical emission spectrometry (ICP-OES)}

ICP analysis of the supernatant from the same experiments from Figure 1 is depicted in Figure 2. Results are only shown for silicates and aluminates because these are the major dissolved materials from the precursors. However, trace elements such as Fe and Ca were also found in solution. This 
is due to the very low concentration of these elements in the FA as well as their slow reactions. Of particular interest was the observation that silicate and aluminate do not dissolve with the same dissolution kinetics (Figures 2a and b). Aluminate dissolves faster and is more soluble than silicate at lower temperatures, as indicated by the increase in the $\mathrm{Si} / \mathrm{Al}$ mass ratio as time and temperature increases. The $\mathrm{Si} / \mathrm{Al}$ mass ratio of the dissolved materials increased from initially 3.8 to 5.3 within $24 \mathrm{~h}$ when the dissolution temperature is $65^{\circ} \mathrm{C}$. This observation is in agreement with previous FA dissolution studies (Fernández-Jiménez et al., 2005; Sagoe-Crentsil and Weng, 2007). By keeping the dissolution duration at $2 \mathrm{~h}$ and increasing the dissolution temperature from $25^{\circ} \mathrm{C}$ to $145^{\circ} \mathrm{C}$, the $\mathrm{Si} / \mathrm{Al}$ mass ratio increases from 2.2 to 6.4 . This means that the temperature has a higher effect on the silicate dissolution rather than the aluminate. Due to the fact that the aluminate component tends to dissolve easier than the silicate component, that total dissolved silicate is still higher than total dissolved aluminate in all samples and that a condensation of silicate species is not a preferred reaction, it can be assumed that all dissolved aluminate anions are covered with up to four neighbouring silicates (De Silva et al., 2007). Figure 2c is in agreement with Figure 1c, where the dissolution rates of aluminate and silicate species are almost constant at different $\mathrm{NaOH}$ molarities. 

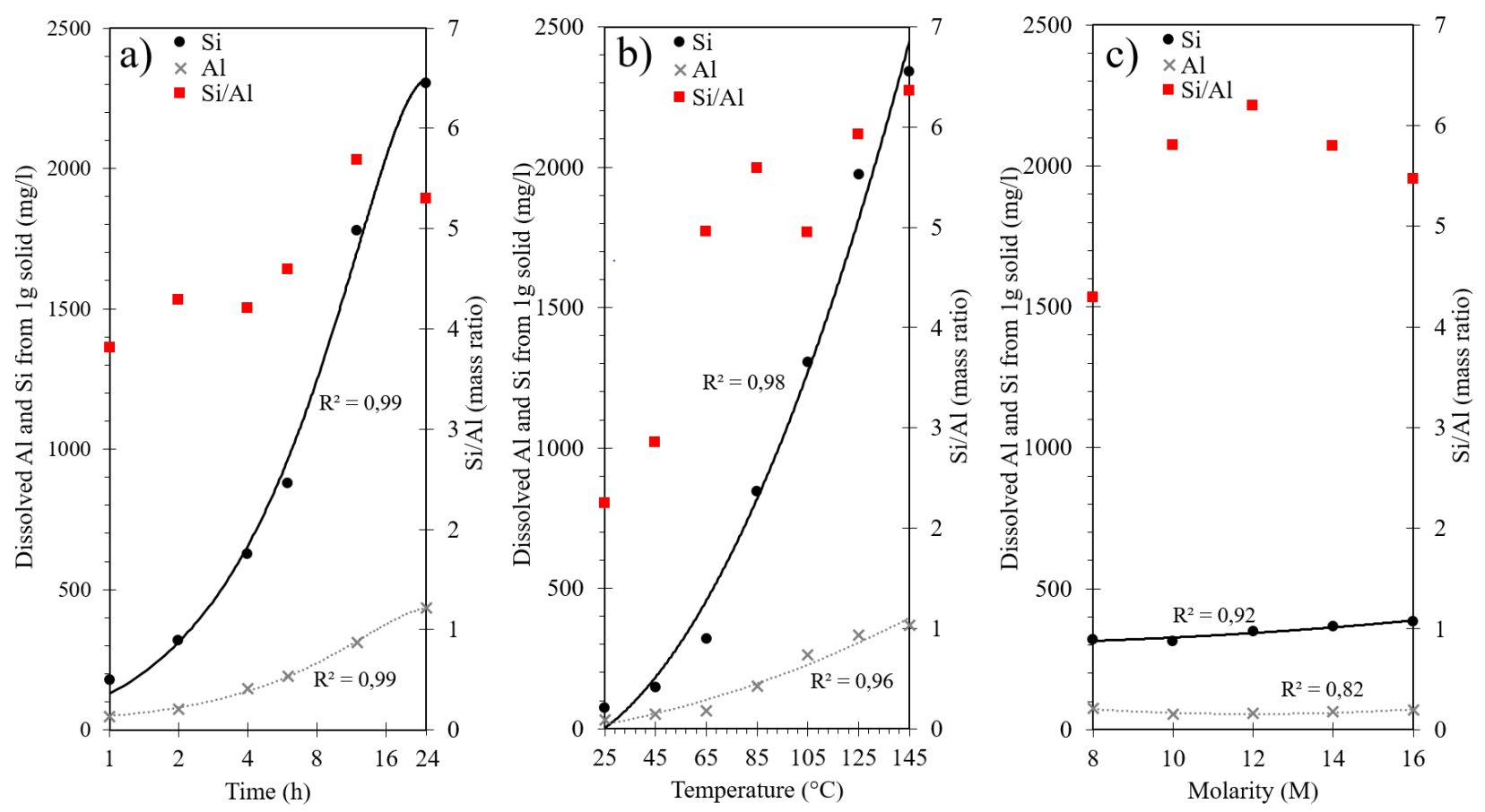

Figure 2: ICP results for dissolved $\mathrm{Al}$ and $\mathrm{Si}$ from $1 \mathrm{~g}$ FA sample in $1000 \mathrm{ml} \mathrm{NaOH}$ solution as a function of a) time; b) temperature and c) $\mathrm{NaOH}$ molarity. Unless specifically varied, the temperatures were $65^{\circ} \mathrm{C}$, dissolution duration was $2 \mathrm{~h}$ and $\mathrm{NaOH}$ molarity $8 \mathrm{M} . \mathrm{R}^{2}$ is a statistical measure of how close the data are to the fitted regression line.

\subsection{Undissolved FA precursors - Infrared vibrational characteristics}

Results of IR analysis of the residual undissolved precursor are compared with the initial FA in Figure 3. For better comparability of the main structural network bonding vibrations, the intensity of all data has been normalized in the range from 800 to $1300 \mathrm{~cm}^{-1}$. As temperature or time increases, the initial broad band at $1056 \mathrm{~cm}^{-1}$ in untreated FA narrows and shifts to slightly higher values of 1074 or $1068 \mathrm{~cm}^{-1}$ respectively. These changes indicate an increase of the length of silicate chains and an increase in the degree of crystallization of the undissolved precursors (Yankwa Djobo et al., 2016). This shows that the amorphous phases have been effectively dissolved and only the crystalline phases remain in the sample. As already expected from Figures 
$1 \mathrm{c}$ and $2 \mathrm{c}$, a change of $\mathrm{NaOH}$ concentration does not affect that band at $1056 \mathrm{~cm}^{-1}$. Other changes can be seen for the bands at 1164-1166 and $871-877 \mathrm{~cm}^{-1}$, which become better resolved with higher temperature and longer dissolution durations. These bands correspond to Si-O-Si bridge vibrations (1164-1166 $\left.\mathrm{cm}^{-1}\right)$ and $\mathrm{Si}-\mathrm{O}^{-}$terminal bond vibrations $\left(871-877 \mathrm{~cm}^{-1}\right)$ (Criado et al., 2007). The emergence of these bands is consistent with the increase of the degree of crystallinity of the undissolved precursors.
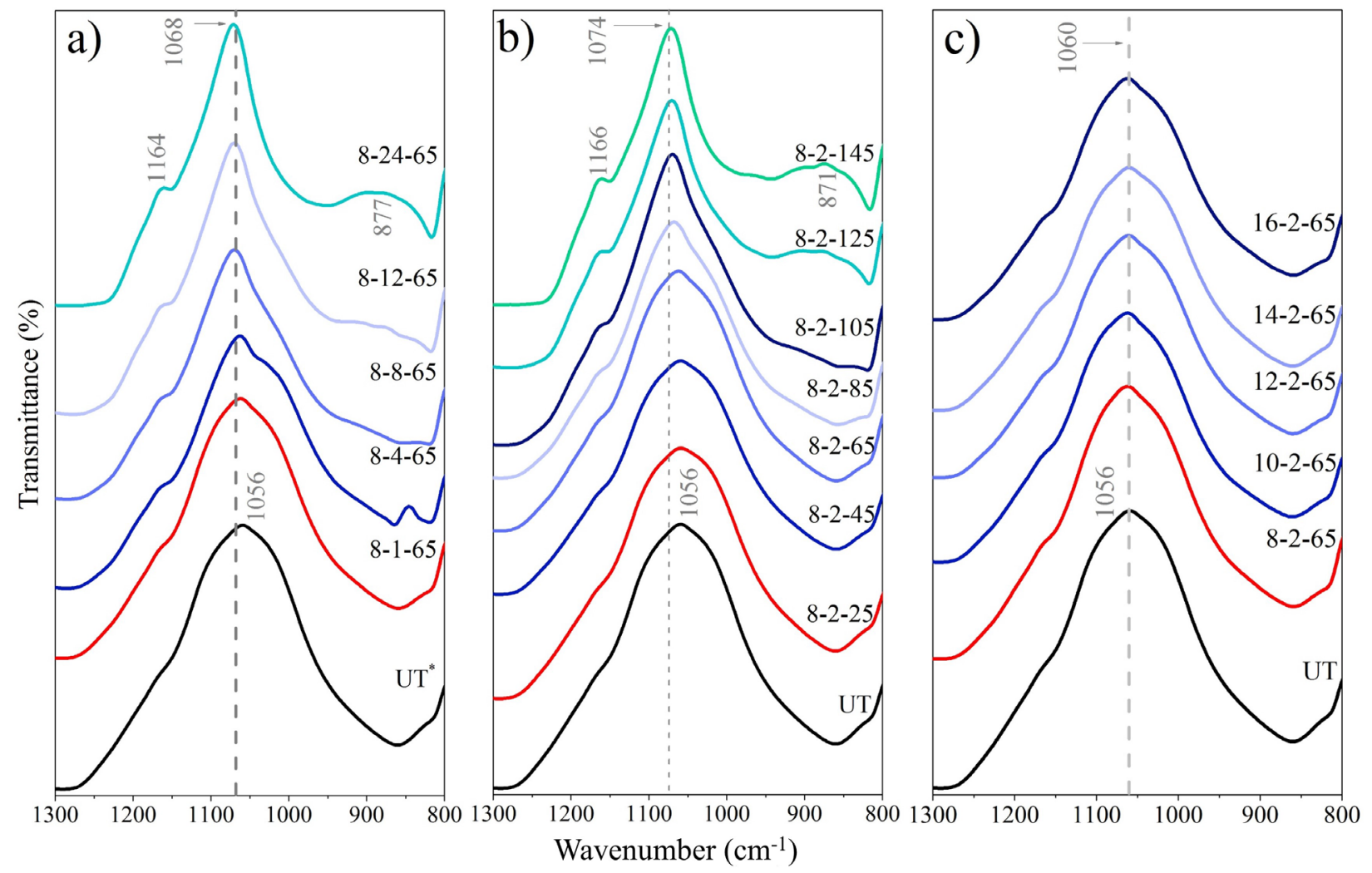

Figure 3: FTIR spectra of the undissolved FA particles in $\mathrm{NaOH}$ as a function of a) time; $b$ ) temperature and c) $\mathrm{NaOH}$ molarity ( ${ }^{*}$ Untreated FA). To distinguish between the various tests, following nomenclature was used: molarity-time-temperature, similar to Table 2. 


\subsection{Undissolved FA precursors - X-Ray Diffraction Analysis (XRD)}

X-ray diffraction patterns of FA residues are shown in Figure 4. Crystalline minerals in the asreceived sample remained independently of the different dissolution process variables applied. The only observable changes were the peaks of mullite and hematite, which remained during dissolution of the amorphous phase and even are better resolved. It is worth noting that magnetite iron oxides in the as-received fly ash might be transformed into hematite during the course of the dissolution process. Such secondary mineral formation has previously been reported with disposed FA over time, equation 4 (Donahoe, 2004).

$$
2 \mathrm{Fe}_{3} \mathrm{O}_{4}+0.5 \mathrm{O}_{2} \rightarrow 3 \mathrm{Fe}_{2} \mathrm{O}_{3}
$$

The amorphous hump, which is expected at around $\sim 20-302 \Theta$ and used as an indication for the reactive phase in geopolymers precursors, is relatively weak and difficult to identify. Therefore, it cannot be used as a clear indication that all reactive material has been dissolved. 


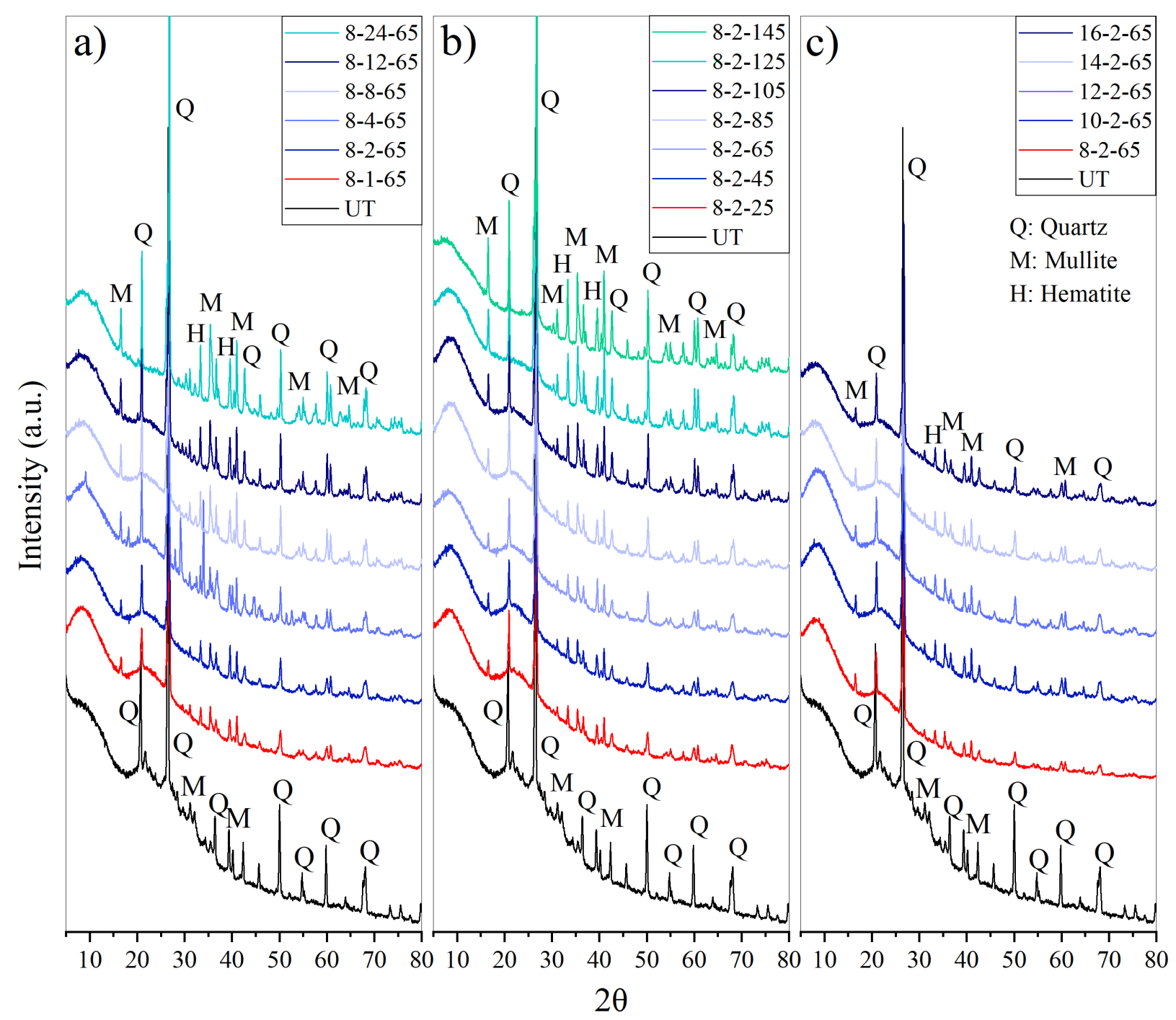

Figure 4: $\mathrm{XRD}$ patterns of undissolved FA particles in $\mathrm{NaOH}$ by variation of a) time; $b$ ) temperature and c) $\mathrm{NaOH}$ molarity. To distinguish between the various tests, following nomenclature was used: molarity-time-temperature, similar to Table 2 .

\subsection{Undissolved FA precursors - Field Emission Scanning Electron Microscopy (FESEM)}

Figure 5a shows the as-received particles of FA. It can be seen that the particles are round since the most stable shape (spherical) is obtained as result of equilibrium between surface tension forces 
on molten droplets and the intrinsic pressure of the internal hot gas during coal combustion ( $\underline{\mathrm{Li} \mathrm{et}}$ al., 2013; Ranjbar and Kuenzel, 2017a).

Figure $5 \mathrm{~b}$ shows the undissolved residue of FA particles which were exposed to $8 \mathrm{M} \mathrm{NaOH}$ for 2 $\mathrm{h}$ at $25^{\circ} \mathrm{C}$. As observed, the dissolution kinetics of the particles are different, some shells started to dissolve whereas others remained intact. Figures $5 \mathrm{c}$ and d show that at 45 and $65{ }^{\circ} \mathrm{C}$ respectively, most of FA particles are partially reacted and due to dissolution of the amorphous fraction they are perforated or partially dissolved. Figures $5 \mathrm{e}$ and $\mathrm{f}$ show that when the temperature is increased above $105^{\circ} \mathrm{C}$, the vitreous fraction is almost completely dissolved and the residue material consists almost entirely of unreacted crystalline phases. A similar dissolution behaviour has already been reported for cenospheres (Fomenko et al., 2015; Ranjbar and Kuenzel, 2017a; Vassilev et al., 2004). It has been shown that cenospheres consist mainly of Si and Al plus some impurities such as $\mathrm{Fe}$ and $\mathrm{Ca}$. These elements are often presented as mixtures of amorphous phases and different crystalline structures such as mullite, magnetite, quartz, lime and periclase (Ranjbar and Kuenzel, 2017a). The crystalline phases form the skeleton structure of the cenosphere particles (Fomenko et al., 2015; Vassilev et al., 2004) which covered by approximately $90 \mathrm{wt} . \%$ of an amorphous glass (Sarkar et al., 2007; Sokol et al., 2000). The glassy layer is reactive and dissolvable in the presence of alkali or acidic agents such as $\mathrm{NaOH}$ or hydrofluoric acid. 


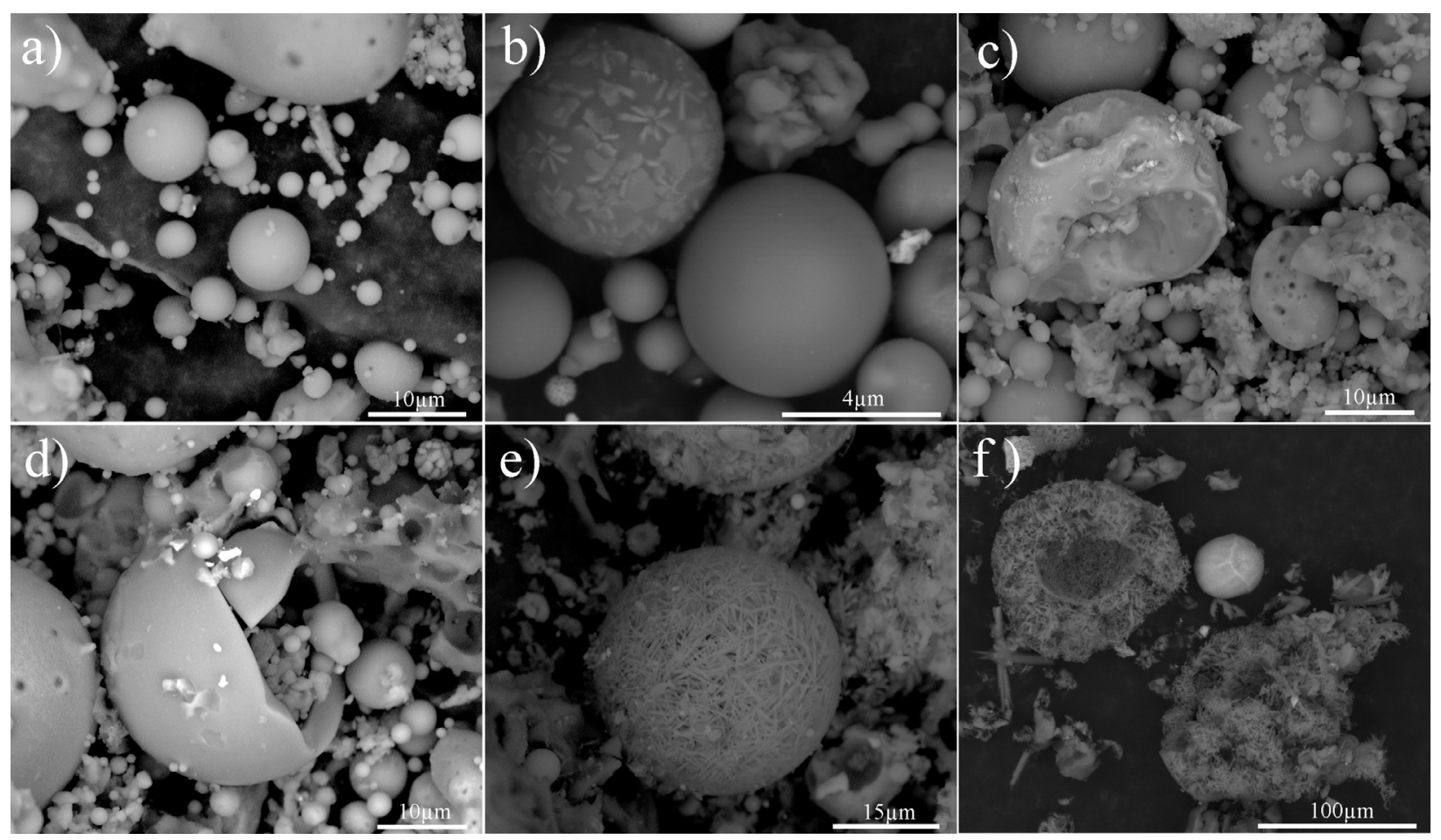

Figure 5: SEM images of: a) As-received FA particles and undissolved residual FA particles treated at b) $25^{\circ} \mathrm{C}$; c) $45^{\circ} \mathrm{C}$; d) $65^{\circ} \mathrm{C}$; e) $105^{\circ} \mathrm{C}$; and f) $145^{\circ} \mathrm{C}$. Dissolution time for all samples was $2 \mathrm{~h}$. Magnification has been adjusted for each figure.

Figure 6 presents quantified $\mathrm{Si}, \mathrm{Al}$ and $\mathrm{Fe}$ concentrations in the as-received FA sample and undissolved residues after dissolution tests at various temperatures for $2 \mathrm{~h}$ in $8 \mathrm{M} \mathrm{NaOH}$. As dissolution increases with increasing temperature (e.g. Figure $6 \mathrm{~b}$ ) the remaining undissolved FA particles are enriched in $\mathrm{Fe}$ and $\mathrm{Al}$ and depleted in $\mathrm{Si}$. The decrease of $\mathrm{Si}$ is due to the dissolution of the glassy phase. However, the unexpected increase of $\mathrm{Al}$ is due to the resistance of mullite to alkali dissolution (Ranjbar and Kuenzel, 2017a), which is supported by the XRD results in Figure $4 b$. 


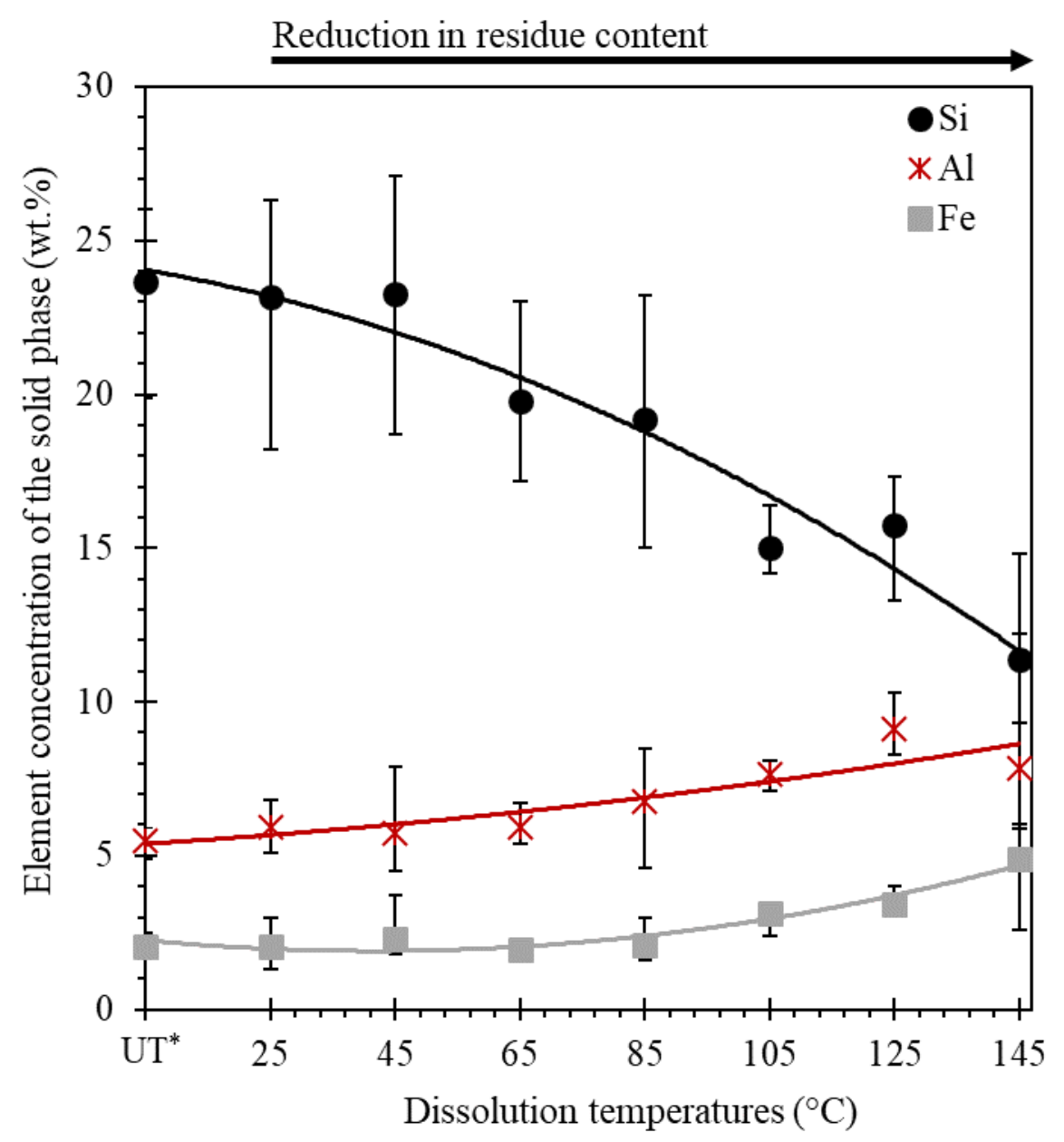

Figure 6: Major elemental concentration of the FA residues measured by EDS analysis of SEM samples. The dissolution duration was $2 \mathrm{~h}$. The remaining amount to obtain an elemental concentration of $100 \%$ is oxide.

\subsection{Origin of unreactive FA particles}

The particle size, SEM and XRD data reveal that FA does not contain a uniform particle mix. Based on our study, we propose that the particles present in FA can be classified into three main groups: 
- Reactive: aluminosilicates with high amorphous fractions which are fully reacted during geopolymerisation.

- Partially reactive: cenospheres, which are partially dissolved when they subjected to highly alkaline solutions.

- Inert: metal oxides, mainly quartz and iron oxides which do not react during geopolymerisation and remain intact in the matrix.

The particle types described above are schematically represented in Figure 7. These particles are a direct result of the physicochemical environment of the coal combustion process (Ghosal and

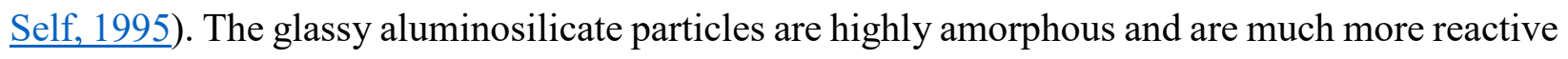
than cenospheres. The amorphous content (positive variable) and the inert iron oxide and quartz content (negative variable) have to be considered in mix design calculations for geopolymer cement formulations. Cenospheres consist of a crystal skeleton covered by a glassy shell and only the glassy phase dissolves (Ranjbar and Kuenzel, 2017a). It is possible that a geopolymerisation is either too fast or new gel forms on top of the cenosphere skeleton, since SEM images, where a "fully naked" cenosphere, containing just the crystal skeleton, as shown in Figure 5e and f, have never been reported. Typical published BSE/SEM images of FA based geopolymers are shown in Figure 8. There are two possibilities to create BSE/SEM images: polished and fractured sample, see Figure $8 \mathrm{a}$ and Figure $8 \mathrm{~b}$ and $\mathrm{c}$. In these images, the unreacted and partially reacted particles have been highlighted. It can be seen that from Figure 8a, it is difficult to identify partially reactive particles and only fractured samples can be used. However, by using polished samples and BSE, it is possible to characterise the sample by the different grey levels. The brighter the area is, the higher is the atomic number. The highest atomic number has Fe, hence unreacted magnetite particles are clearly noticeable. Next, unreacted aluminosilicates and cenospheres exhibit a weaker 
difference in grey-level from the surrounding geopolymer binder and can be identified as darker areas. Therefore, from BSE images, the inert particles in FA based geopolmyers can be categorized into two major groups with distinct atomic number ranges: (i) magnetite and (ii) unreactive aluminosilicates/cenospheres. Figure $8 \mathrm{~b}$ shows a partially dissolved cenosphere particle. From this only the outer shell of cenosphere particle is slightly dissolved and crystalline skeleton can merely be estimated. This is in agreement with Figure 5d which does not show any surface dissolution. Only when the temperature is higher, the crystalline skeleton becomes fully visible. Based on this, it is proposed that only minor parts of the shell are dissolved. Similarly, iron oxides are insoluble and inert in the alkali environment of geopolymer cements and remain intact, either as hollow spheres or solid particles.

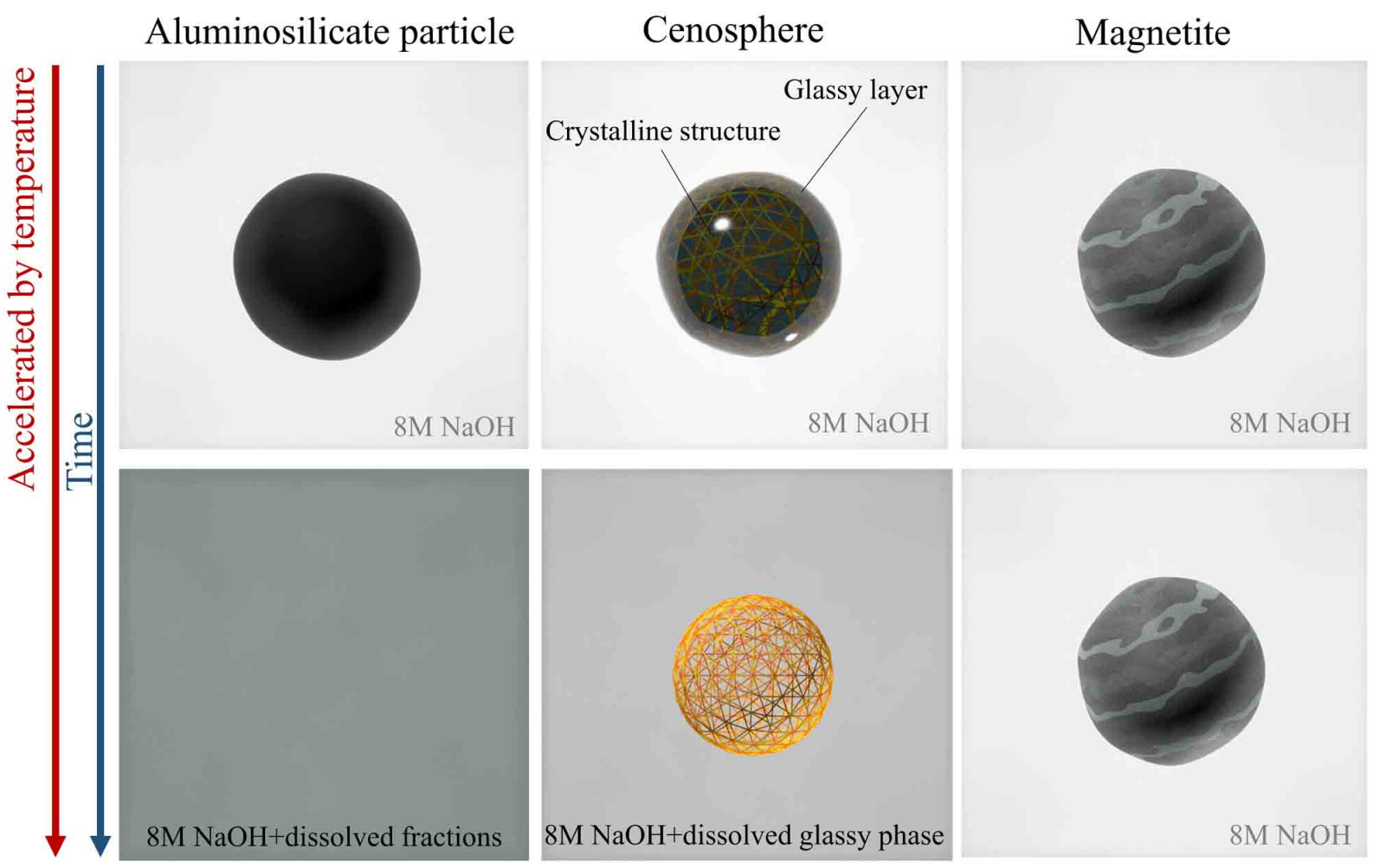

Figure 7: Schematic images of different FA particles and their changes during a dissolution test with $8 \mathrm{M} \mathrm{NaOH}$ solution. 

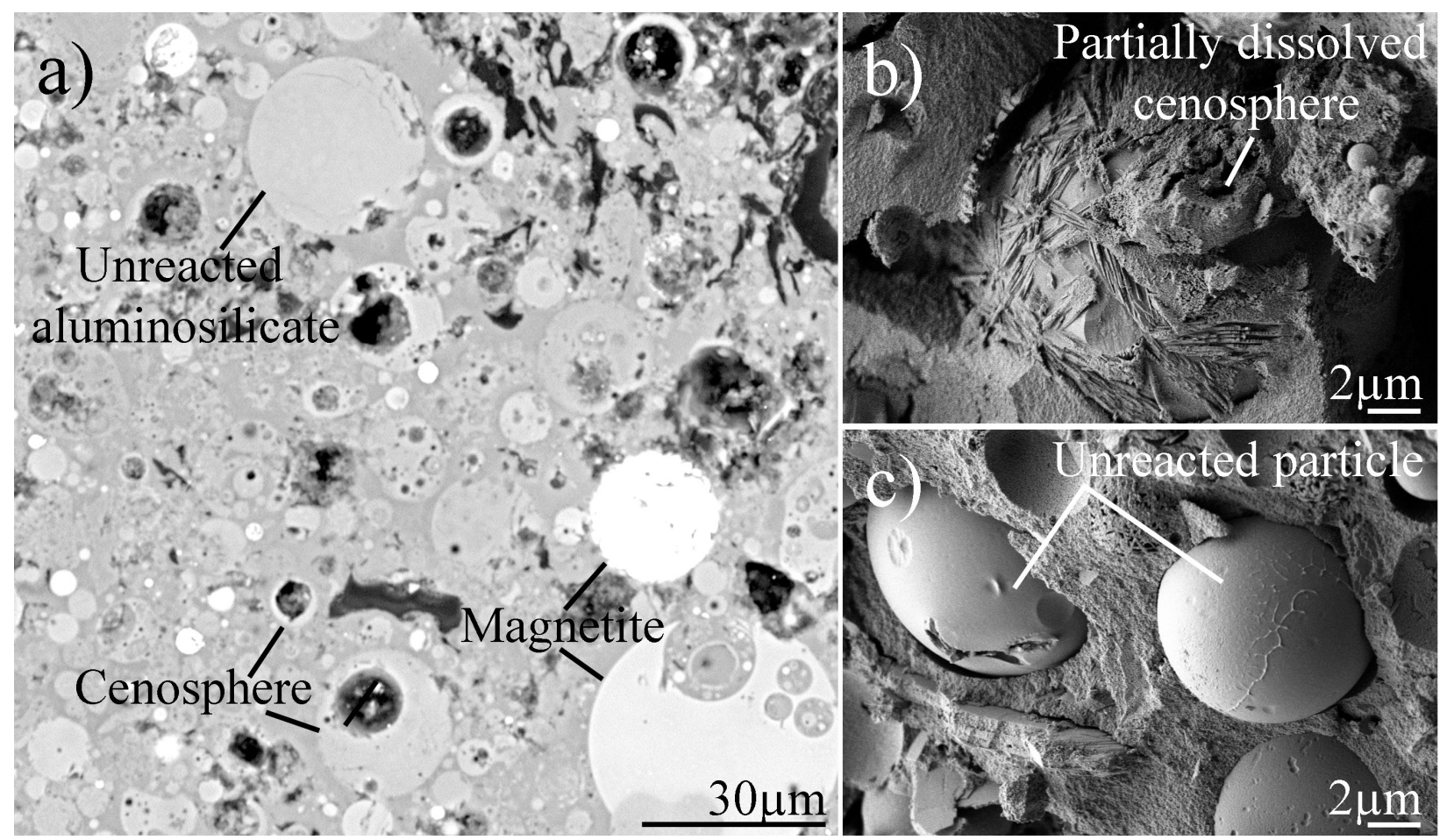

Figure 8: a) BSE on a polished sample; b) and c) SEM images of fractured FA based geopolymers.

\subsection{Comparison of dissolution method (ICP) and elemental analysis of undissolved mass (EDX) to characterise the reactive amount}

Based on the findings, it is possible to use two different methods to quantify the reactive material. One method is by analysis of the dissolved Al and Si using ICP, the other method uses the mapping function of EDX to determine the $\mathrm{Al}$ and $\mathrm{Si}$ concentration in the un-dissolved material. After the analysis, the amount of reactive $\mathrm{Si}$ and $\mathrm{Al}$ can be calculated. This information is important because the $\mathrm{Si} / \mathrm{Al}$ ratio influences the mechanical properties of the binder (De Silva et al., 2007; $\underline{\text { Provis and }}$ Van Deventer, 2009).

Figure 9a compares the amount of the undissolved FA measured by the residual mass retained on the filter after the dissolution test with the $\mathrm{Si}$ and $\mathrm{Al}$ content in the liquid phase from the same tests, measured by ICP as a function of temperature. Figure $9 \mathrm{~b}$ shows the molar $\mathrm{Si} / \mathrm{Al}$ ratio in 
solution measured by ICP analysis of the liquid phase and by EDX analysis of the undissolved residue.

Figures $9 \mathrm{a}$ and $\mathrm{b}$ show that there is some measurement error for the two methods to determine reactive material content and reactive material composition. At lower temperatures the discrepancy between methods in Figures $9 \mathrm{a}$ and $\mathrm{b}$ is larger. It is assumed that the discrepancies are due to several reasons.

1) The remaining mass from ICP data has been calculated considering only Si and Al, whereas the possible dissolution of $\mathrm{Na}, \mathrm{K}$, and $\mathrm{Ca}$ have been ignored. At low temperatures, the dissolution of $\mathrm{Si}$ and $\mathrm{Al}$ is reduced but the solubility of $\mathrm{Na}, \mathrm{K}$ and $\mathrm{Ca}$ remains high due to a higher dissolving kinetic. This means that the undissolved mass is overestimated by the ICP method at low temperatures.

2) Extreme fine particles are lost during washing and neutralisation of the insoluble mass retained on the filter, meaning that the undissolved mass is underestimated by the filter mass method.

3) From Figure $9 \mathrm{~b}$ it is assumed that during the washing and neutralisation process, further $\mathrm{Al}$ is dissolved from FA. This $\mathrm{Al}$ dissolution is due to the fact that a lot of water is required to obtain a pH-neutral residue. We found that at the beginning of the washing process, the $\mathrm{pH}$ increases to about 14 and remains so high for a long time. Due to this, further $\mathrm{Al}$ dissolves and a higher Si concentration is measured using EDS at lower temperatures. Only when the dissolution temperature is high enough all reactive $\mathrm{Si}$ and $\mathrm{Al}$ is dissolved within $2 \mathrm{~h}$ and a similar $\mathrm{Si} / \mathrm{Al}$ ratio is measured.

Regardless, when the dissolution temperature is above $65^{\circ} \mathrm{C}$ both the ICP and EDS methods produced similar data. However, it is recommend to assess the reactive material composition by 
using ICP. This method is suggested for practical reasons and because of homogeneity in the solution which is analysed by ICP. When the EDS mapping is used, only a small area of the sample is analysed and the homogeneity cannot be guaranteed.

The results show that FA is a mixture of reactive, partially reactive and inert materials. The determination of reactive and inert materials is fairly simple because they either dissolve or remain in the residue, but the quantification of the partially reactive material can be an issue. Temperature dissolution measurements have demonstrated that the partially reactive phase is temperature dependent, dissolves relatively slowly and contains mostly silicon. This slow dissolution can result in a misleading interpretation of soluble silicon and lead to an incorrect calculation of the molar $\mathrm{Si} / \mathrm{Al}$ ratio of resulting binders. To determine the reactive/partially reactive amount of material which will participate during the reaction, it is recommended to determine the soluble amount at the curing temperature using a solution between $8 \mathrm{M}$ and $16 \mathrm{M} \mathrm{NaOH}$. As dissolution duration, the curing time at curing temperature has to used. This procedure is justified because the dissolution kinetics of partially reactive materials at room temperature is neglectable. 

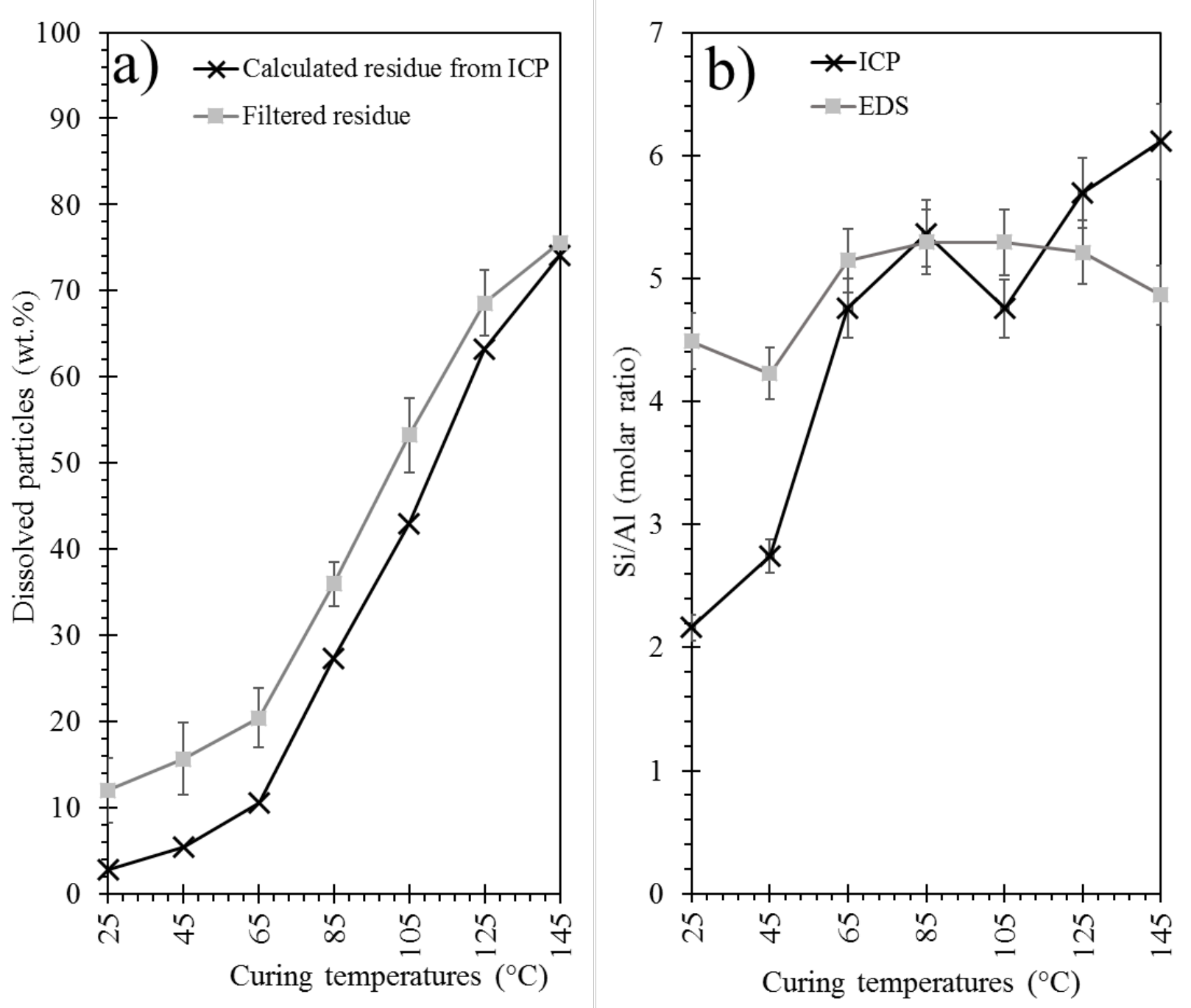

Figure 9: Comparison of a) the undissolved mass using dissolution method and calculated one based on ICP; b) estimation of molar $\mathrm{Si} / \mathrm{Al}$ ratio of dissolved mass using ICP and EDS analysis.

Dissolution duration was $2 \mathrm{~h}$.

\section{Conclusion}

This study focused on the dissolution process of FA subjected to alkali activation. It was shown that the dissolution of FA is dominated by temperature and time and independent of $\mathrm{NaOH}$ molarity when between 8 and 16M. This is associated with the increase in the kinetic energy of 
the system at higher temperatures which breaks the solute molecular bonds by solvent molecules and hold an intermolecular attraction, more effectively. Based on FTIR, ICP, XRD and SEM-EDS it was shown that FA consists of three different materials: reactive, partially reactive, and inert. The reactive precursor dissolves completely during geopolymerisation. The partially reactive materials are cenospheres. There only the outer vitreous Si shell dissolves and the inert material remains un-reacted. To avoid overestimation during reactive measurements, an adapted dissolution method is proposed. It is suggested to determine the soluble amount at the curing temperature using a $\mathrm{NaOH}$ solution of at least $8 \mathrm{M}$. The dissolution duration and temperature has be the same as the initial curing conditions. After filtration, the soluble amount has to be quantified by ICP. From this data, the non-reactive amount can be calculated.

\section{Acknowledgement}

The research leading to these results has received funding from the European Union's Horizon 2020 research and innovation program under the Marie Sklodowska-Curie grant agreement no. 713683 (COFUNDfellowsDTU). Furthermore, the authors would like to acknowledge the contribution of Dr. Shane Donatello and Dr. Jean Noel Yankwa Djobo for fruitful discussions.

\section{References}

Aredes, F.G.M., Campos, T.M.B., Machado, J.P.B., Sakane, K.K., Thim, G.P., Brunelli, D.D., 2015. Effect of cure temperature on the formation of metakaolinite-based geopolymer. Ceramics International 41(6), 7302-7311.

Aughenbaugh, K.L., 2013. Fly ash-based geopolymers: identifying reactive glassy phases in potential raw materials.

Aughenbaugh, K.L., Chancey, R.T., Stutzman, P., Juenger, M.C., Fowler, D.W., 2013. An examination of the reactivity of fly ash in cementitious pore solutions. Materials and structures 46(5), 869-880. 
Brouwers, H.J.H., Van Eijk, R.J., 2002. Fly ash reactivity: extension and application of a shrinking core model and thermodynamic approach. J. Mater. Sci. 37(10), 2129-2141.

Chen-Tan, N.W., Van Riessen, A., Ly, C.V., Southam, D.C., 2009. Determining the reactivity of a fly ash for production of geopolymer. J. Am. Ceram. Soc. 92(4), 881-887.

Cheng, T.W., Chiu, J.P., 2003. Fire-resistant geopolymer produced by granulated blast furnace slag. Minerals Engineering 16(3), 205-210.

Chindaprasirt, P., Chareerat, T., Sirivivatnanon, V., 2007. Workability and strength of coarse high calcium fly ash geopolymer. Cement and concrete composites 29(3), 224-229.

Criado, M., Fernández-Jiménez, A., Palomo, A., 2007. Alkali activation of fly ash: effect of the $\mathrm{SiO}_{2} / \mathrm{Na}_{2} \mathrm{O}$ ratio: Part I: FTIR study. Microporous Mesoporous Mat. 106(1), 180-191.

Davidovits, J., 2008. Geopolymer chemistry and applications. Geopolymer Institute.

De Silva, P., Sagoe-Crenstil, K., Sirivivatnanon, V., 2007. Kinetics of geopolymerization: role of $\mathrm{Al}_{2} \mathrm{O}_{3}$ and $\mathrm{SiO}_{2}$. Cem. Concr. Res. 37(4), 512-518.

Djobo, J.N.Y., Tchakouté, H.K., Ranjbar, N., Elimbi, A., Tchadjié, L.N., Njopwouo, D., 2016. Gel Composition and Strength Properties of Alkali-Activated Oyster Shell-Volcanic Ash: Effect of Synthesis Conditions. Journal of the American Ceramic Society.

Donahoe, R.J., 2004. Secondary mineral formation in coal combustion byproduct disposal facilities: implications for trace element sequestration. Geological Society, London, Special Publications 236(1), 641-658.

Fang, G., Ho, W.K., Tu, W., Zhang, M., 2018. Workability and mechanical properties of alkaliactivated fly ash-slag concrete cured at ambient temperature. Construction and Building Materials 172, 476-487.

Fernández-Jiménez, A., Palomo, A., 2005. Composition and microstructure of alkali activated fly ash binder: effect of the activator. Cement and concrete research 35(10), 1984-1992.

Fernández-Jiménez, A., Palomo, A., Criado, M., 2005. Microstructure development of alkaliactivated fly ash cement: a descriptive model. Cem. Concr. Res. 35(6), 1204-1209.

Fomenko, E.V., Anshits, N.N., Vasilieva, N.G., Mikhaylova, O.A., Rogovenko, E.S., Zhizhaev, A.M., Anshits, A.G., 2015. Characterization of fly ash cenospheres produced from the combustion of Ekibastuz coal. Energy \& Fuels 29(8), 5390-5403.

Fraay, A.L.A., Bijen, J.M., De Haan, Y.M., 1989. The reaction of fly ash in concrete a critical examination. Cem. Concr. Res. 19(2), 235-246.

Ghosal, S., Self, S.A., 1995. Particle size-density relation and cenosphere content of coal fly ash. Fuel 74(4), 522-529.

Gutteridge, W.A., 1979. On the dissolution of the interstitial phases in Portland cement. Cem. Concr. Res. 9(3), 319-324.

Hajimohammadi, A., J.L. Provis, and J.S.J van Deventer, 2010. Effect of alumina release rate on the mechanism of geopolymer gel formation. J. Am. Chem. Soc. 22.

Hardjito, D., Wallah, S.E., Sumajouw, D.M., Rangan, B.V., 2004. On the development of fly ashbased geopolymer concrete. Materials Journal 101(6), 467-472.

Komnitsas, K., Zaharaki, D., 2007. Geopolymerisation: A review and prospects for the minerals industry. Minerals engineering 20(14), 1261-1277.

Kuenzel, C., Neville, T., Donatello, S., Vandeperre, L., Boccaccini, A., Cheeseman, C., 2013. Influence of metakaolin characteristics on the mechanical properties of geopolymers. Applied Clay Science 83, 308-314. 
Kuenzel, C., Vandeperre, L.J., Donatello, S., Boccaccini, A.R., Cheeseman, C., 2012. Ambient temperature drying shrinkage and cracking in metakaolin-based geopolymers. Journal of the American Ceramic Society 95(10), 3270-3277.

Li, S., Roy, D.M., Kumar, A., 1985. Quantatative determination of pozzolanas in hydrated systems of cement or $\mathrm{Ca}(\mathrm{OH})_{2}$ with fly ash or silica fume. Cem. Concr. Res. 15(6), 1079-1086.

Li, Y., Gao, X., Wu, H., 2013. Further investigation into the formation mechanism of ash cenospheres from an Australian coal-fired power station. Energy Fuels 27(2), 811-815.

Luke, K., Glasser, F.P., 1987. Selective dissolution of hydrated blast furnace slag cements. Cem. Concr. Res. 17(2), 273-282.

Mo, B.-h., Zhu, H., Cui, X.-m., He, Y., Gong, S.-y., 2014. Effect of curing temperature on geopolymerization of metakaolin-based geopolymers. Applied Clay Science 99, 144-148.

Ogawa, K., Uchikawa, H., Takemoto, K., Yasui, I., 1980. The mechanism of the hydration in the system C3S-pozzolana. Cem. Concr. Res. 10(5), 683-696.

Ohsawa, S., Asaga, K., Goto, S., Daimon, M., 1985. Quantitative determination of fly ash in the hydrated fly ash-CaSO ${ }_{4} \cdot 2 \mathrm{H}_{2} \mathrm{O} \cdot \mathrm{Ca}(\mathrm{OH})_{2}$ system. Cem. Concr. Res. 15(2), 357-366.

Pietersen, H.S., Fraay, A.L.A., Bijen, J.M., 1989. Reactivity of fly ash at high pH, in fly ash and coal conversion by-products: Characterization, utilization and disposal VI, Materials research society symposium proceedings. Materials Research Society.

Provis, J., Van Deventer, J., 2007. Geopolymerisation kinetics. 2. Reaction kinetic modelling. Chem. Eng. Sci. 62(9), 2318-2329.

Provis, J.L., van Deventer, J.S., 2007. Geopolymerisation kinetics. 1. In situ energy-dispersive Xray diffractometry. Chem. Eng. Sci. 62(9), 2309-2317.

Provis, J.L., Van Deventer, J.S.J., 2009. Geopolymers: structures, processing, properties and industrial applications. Elsevier.

Ranjbar, N., Kashefi, A., Maheri, M.R., 2018. Hot-pressed geopolymer: Dual effects of heat and curing time. Cement and Concrete Composites 86, 1-8.

Ranjbar, N., Kuenzel, C., 2017a. Cenospheres: A review. Fuel 207, 1-12.

Ranjbar, N., Kuenzel, C., 2017b. Influence of preheating of fly ash precursors to produce geopolymers. Journal of the American Ceramic Society.

Ranjbar, N., Mehrali, M., Alengaram, U.J., Metselaar, H.S.C., Jumaat, M.Z., 2014a. Compressive strength and microstructural analysis of fly ash/palm oil fuel ash based geopolymer mortar under elevated temperatures. Constr Build Mater 65, 114-121.

Ranjbar, N., Mehrali, M., Behnia, A., Alengaram, U.J., Jumaat, M.Z., 2014b. Compressive strength and microstructural analysis of fly ash/palm oil fuel ash based geopolymer mortar. Mater. Des. 59, 532-539.

Ranjbar, N., Mehrali, M., Behnia, A., Pordsari, A.J., Mehrali, M., Alengaram, U.J., Jumaat, M.Z., 2016. A comprehensive study of the polypropylene fiber reinforced fly ash based geopolymer. PloS one 11(1), e0147546.

Ranjbar, N., Mehrali, M., Maheri, M.R., Mehrali, M., 2017. Hot-pressed geopolymer. Cement and Concrete Research 100, 14-22.

Ruiz-Santaquiteria C, F.-J.A., Palomo A, 2011. Quantitative determination of reactive SiO2 and $\mathrm{A} 12 \mathrm{O} 3$ in aluminosilicate materials, 13th International Congress on the Chemistry of Cement Madrid, Spain.

Sagoe-Crentsil, K., Weng, L., 2007. Dissolution processes, hydrolysis and condensation reactions during geopolymer synthesis: Part II. High Si/Al ratio systems. Journal of Materials Science 42(9), 3007-3014. 
Sarkar, A., Rano, R., Mishra, K., Mazumder, A., 2007. Characterization of cenospheres collected from ash-pond of a super thermal power plant. Energy Sources, Part A: Recovery, Utilization, and Environmental Effects 30(3), 271-283.

Sokol, E., Maksimova, N., Volkova, N., Nigmatulina, E., Frenkel, A., 2000. Hollow silicate microspheres from fly ashes of the Chelyabinsk brown coals (South Urals, Russia). Fuel Processing Technology 67(1), 35-52.

Swanepoel, J.C., Strydom, C.A., 2002. Utilisation of fly ash in a geopolymeric material. Applied Geochemistry 17(8), 1143-1148.

Tchadjié, L., Djobo, J., Ranjbar, N., Tchakouté, H., Kenne, B., Elimbi, A., Njopwouo, D., 2016. Potential of using granite waste as raw material for geopolymer synthesis. Ceramics International 42(2), 3046-3055.

Vassilev, S.V., Menendez, R., Diaz-Somoano, M., Martinez-Tarazona, M.R., 2004. Phase-mineral and chemical composition of coal fly ashes as a basis for their multicomponent utilization. 2. Characterization of ceramic cenosphere and salt concentrates. Fuel 83(4), 585-603.

Wang, H., Li, H., Yan, F., 2005. Synthesis and mechanical properties of metakaolinite-based geopolymer. Colloids and Surfaces A: Physicochemical and Engineering Aspects 268(1), 1-6.

Weng, L., Sagoe-Crentsil, K., 2007. Dissolution processes, hydrolysis and condensation reactions during geopolymer synthesis: Part I—Low Si/Al ratio systems. Journal of Materials Science 42(9), 2997-3006.

Yankwa Djobo, J.N., Elimbi, A., Tchakoute, H.K., Kumar, S., 2016. Mechanical activation of volcanic ash for geopolymer synthesis: effect on reaction kinetics, gel characteristics, physical and mechanical properties. RSC Advances 6(45), 39106-39117.

Zuhua, Z., Xiao, Y., Huajun, Z., Yue, C., 2009. Role of water in the synthesis of calcined kaolinbased geopolymer. Applied Clay Science 43(2), 218-223. 